\title{
Organizational Culture in Higher Education: Learning from the Best
}

\author{
Adela Coman \\ -Associate professor- \\ The University of Bucharest, Romania \\ adela_coman2003@yahoo.com
}

Catalina Bonciu

-Professor-

The University of Bucharest, Romania

catalina.bonciu@yahoo.com

\begin{abstract}
In this paper we discuss organizational culture of higher education institutions whose components have been thoroughly described by authors such as Tierney (1988) and Valimaa (1998). We focused on the elements of organizational culture which outlines the identity of a higher education institution: why does the institution exist? How does the institution reach its goals and mission? What does the institution offer to its internal and external public? As such, we analyzed the mission, structure, governance and decision making processes, teaching and research in a comparative perspective: Harvard University (HU) and the University of Bucharest (UB), Romania. By looking into the organizational culture of the best, we learnt some lessons that may inspire, motivate and urge action if UB wants to progress so as to become one day a top leader in higher education worldwide.
\end{abstract}

Keywords: organizational culture, mission, governance, values, teaching and research

\section{Introduction}

Organizations today are knowledge-based and their success depends on flexibility and innovation. An effective reaction to these demands leads not only to changes in individuals and their behavior, but also to innovative changes in organizations to ensure their existence (Read, 1996). It appears that the rate of change is accelerating rapidly as new knowledge and its global diffusion increases (Senge et al, 1999). Creating innovative and adaptable frameworks have a role to play in this change process for survival. The result is that organizations and their leaders try to create an institutional framework in which new ways of motivating people and taking actions will be accepted as basic cultural norms in the midst of technological and societal change. Authors such as Ahmed (1998), Martell (1989), Pheysey (1993), Robbins (1996), Schuster (1986) have emphasized the importance of organizational culture in this context. Organizational culture seems to have an influence on how individuals perceive identity and openness to change in organizations, including higher education institutions.

Students come to believe in their university as the university communicates messages and interacts with them. When the university speaks of its mission, it speaks of helping students. Faculty members and administrators should start from the assumption that the student is a learner who should trust the institution where he/she studies and who should be encouraged to see the learning experience as a personal transformation; this process, at times, will challenge the tastes, desires and preconceived opinions they might have held up till that moment. The student is raw material during the learning process and progress toward a finished product, but a product of their own choosing.

An analysis of organizational culture endows administrators and faculty with information rather implicit about their institution which in turn may help solve some critical dilemmas: how can we design a more flexible structures and governance given 
the rapidly changing environment and declining resources? How can we implement a system of decision making so as to diagnose problems, find solutions and offer programs enrichment to support academic innovation and excellence? How can we use values such as autonomy and freedom to design structures and practices to motivate academics reach their potential while helping students to find their way? The answer to these questions is a good start for managers and administrators who try to improve institutional performance.

To say that higher education institution has excellent results is similar today with acknowledging that it offers excellent research and teaching. An investigation of these activities is useful because they embed skills, qualifications but also symbols and meaning. From this perspective, teaching and research are carriers of organizational culture seen as an interconnected web whose components overlap and connect with one another. Moreover, increasing performance in both teaching and research sends the right message to students and the general public regarding to what the institution does to reach its mission and goals, solve critical problems and build trust in its capacity to do what it has promised.

This paper intends to offer some answers to questions related to organizational culture in higher education institutions. The paper starts with a literature review of organizational culture and its components. We then turned to what we believe is relevant for the identity of a higher education institution: mission, structure, governance and decision making as well as teaching and research. Each of the analyzed elements answers to some questions: why does the organization exist? (mission); how does the organization reach its goals? (structure, governance and decision making); what does the organization do (teaching and research) to effectively meet the needs of internal and external public? In search of answers we made use of a comparative approach, having as mentor Harvard University and as a disciple, the University of Bucharest, Romania. Some answers and lessons are learnt in the end as to how, why and what to improve in order to strengthen the organizational culture and help the disciple innovate and progress.

\section{Organizational culture - a literature review}

Numerous definitions related to the organizational culture are dealt with in the literature. One of the most popular is "the way we do things around here" (Lundy and Cowling, 1996). Martins and Terblanche (2003) understand an organizational culture as the set of subconscious values and beliefs deeply seated in the organizational structure and shared by its members. According to Schein (1985), organizational culture also refers to a set of basic assumptions that worked well in the past and therefore they are accepted as valid assumptions that are maintained within an organization. Since these assumptions are continually tested in attitudes and behaviors and human interactions, we refer to the organizational culture as to the right/appropriate way for taking actions, understanding and solving problems within an organization. Beliefs, norms, values, philosophy, rules of the game and feelings, the components of routine behavior, all are part of organizational culture (Hellriegel et al, 1998).

An organizational culture is an integral part of the general functioning of an organization. A strong culture is based on shared values and beliefs that ensure that everyone in an organization is on the same track (Robbins, 1996). The role of an organizational culture may be inferred from the general functions and influences that organizational culture exerts on the organization's different processes.

According to Furnham and Gunter (1993), the functions of organizational cultures consist in internal integration and coordination. Internal integration refers to the new members' socializing processes, creating the boundaries of the organization, the feeling of identity and commitment of its members. The coordination function refers to creating a competitive edge, making sense of the environment in terms of acceptable behavior and social system stability which is the social glue that holds the organization together (Martins, 2000). Effective communication is based on shared meanings and beliefs. If the organizational cultures fail to fulfill these functions in an acceptable manner, most likely they may contribute to reducing the organizations' efficiency (Furnham and Gunter, 1999).

Organizations use different resources and processes to guide behavior and change. Managers use rational tools and processes such as setting strategic direction, goals, technology, structures and communication, decision making, cooperation and interpersonal relations meant to do things. Culture, on the other hand, describes the character of an organization and is expressed through symbols, feelings, meanings, behavior, physical settings and artifacts. Resources and processes are tools while culture is thought (Chiritescu, 2016). Therefore, organizational culture complements the rational managerial tools by playing an indirect role in shaping and influencing behavior. The expressive practice of culture 
is rather a reflection of how an organization says things (Coffey et al, 1994). Moreover, the art of expressing why you do what you do, from an organizational culture perspective is a compelling indicator that the organization is on the right track (Sinek, 2009).

There is not abundant research into higher education institutions as organizational cultures. Burton Clarck, for example, has pioneered work on distinctive colleges as cultures (1970), the role of belief and loyalty in college organizations (1971) and organizational sagas as tools for institutional identity (1980). Earlier work has included the study of academic cultures (Becher, 1981; Freedman, 1979; Gaff, J. G. and Wilson, R., 1971), leadership (Chaffee, E. E. and Tierney, W. G., 1988; Tierney, W. G., 1988) and the system of higher education as a culture (Bourdieu, P., 1977; Clarck, B. R., 1984).

Higher education institutions are similar with business organizations in many ways. They have structures and processes, missions, goals and strategies to reach those goals. And, as in the case of business organizations, higher education institutions are influenced by powerful, external forces such as demographic, economic and political conditions; yet they are also shaped by strong forces that emanate from within (Tierney, 1988). This internal dynamic has its roots in the history of the organization and derives its force from its values, processes and goals. A higher education institution's culture is reflected in what is done, how it is done and who is involved in doing it. It concerns decisions, actions and communication, both on an instrumental and a symbolic level. It involves stories, special language, norms, institutional ideology and attitudes that emerge from individual and organizational behavior (Tierney, 1988).

According to Geertz, cultures are "webs...the analysis of it to be therefore not an experimental science in search of law, but an interpretive one in search of meaning" (Geertz, 1973, p. 5). Thus, an analysis of organizational culture of a university occurs as if the institution were an interconnected web that cannot be understood unless one looks not only at the structure and natural laws of that web, but also at the actors; interpretations of the web itself. Organizational culture then is the study of particular webs of significance within an organizational setting.

In universities, leaders and administrators often have only an intuitive grasp of the cultural conditions and influences that enter into their daily decision making. They have only a passive awareness of cultural codes, norms, symbols, beliefs and conventions and tend to recognize organizational culture only when conflicts are about to burst and adverse relationships manifest in a variety of forms. As a result, individuals find themselves dealing with organizational culture in an atmosphere of crisis instead of calm reflection and consensual change (Tierney, 1988).

Our lack of understanding of the role of organizational culture in improving management and institutional performance inhibits our ability to address the challenges that face higher education (Tierney, 1988). As decision making contexts grow in complexity, costs increase and resources become more difficult to allocate, leaders and administrators of higher education may benefit from understanding their institutions as cultural entities. As they make difficult decisions, these need not upscale conflicts. Instead, if they are properly informed by an awareness of culture, an administrator's decisions may contribute to creating a sense of purpose and identity within the institution. Moreover, to implement decisions, leaders and administrators need to understand the university's culture. Only then can they articulate decisions in a way that will speak to the needs of all actors and attract their support (Tierney, 1988).

It is important to understand that as much aware of organizational culture as one can be, recognizing its role and power is not a panacea for solving administrative problems. But a correct interpretation of the organization's culture may provide a critical insight into which of the many possible avenues one may choose from in search of in "one best way" to meet both the academics' needs and the goals of the institution.

\section{Models of organizational culture}

Several authors have tried to describe the relationships between variables of organizational cultures using models: Sathe (1985), Schein (1985), Kreitner and Kinicki (1992).

Starting from the work of Schein (1985), Martins (1997) developed a model bearing in mind the ideal business organization and the role of leadership in creating the ideal organizational culture. Martins' model describes the interaction between the organizational subsystems (goals, values, structural, managerial, technological and psychological and sociological subsystems), the survival functions of external environment (social, industrial and corporate culture) and the internal systems (artifacts, values and basic assumptions) and the dimensions of culture. According to Martins (1997), these 
dimensions of culture refer to the following: mission, external environment, means to achieve objectives, image of the organization, management processes, employees' needs and objectives, interpersonal relationships and leadership.

Organizational mission refers to how the institution's participants define the overarching ideology of the university. The mission of an organization is an interpretive act that provides meaning, direction and purpose (Tierney, 2008). In part, an organization's mission is defined by the history of the institution.

Further, to speak of any social institution is to speak of an organization that exists in an environment. As with the idea of organizational mission, however, how an institution's participants define the environment gets worked out within a cultural framework. That is, from a cultural perspective, the world is socially constructed and how concepts such as environment get defined is not so much a given fact but rather is something constantly considered, redefined and reinterpreted (Tierney, 1994).

Leadership is also a cultural construct that demands investigation when studying colleges and universities. Leaders enact scripts through an interpretive lens that enables them to act and communicate in one way in the organization and another in a different organization. Indeed, who the leaders are and whether the organization permits only formal leaders or relies on informal leaders is contingent on culture. Similarly, the manners in which the organization defines strategy and information are not fixed definitions irrespective of organizational type, but instead revolve around cultural interpretations of what the actors have come to expect about "how we do things around here". People come to believe in their institutions by the manner in which they interact and communicate with one another. Cultural norms surrounding such key issues as how decisions get made and by whom, who is privy to information and how information gets conveyed plays a key role in facilitating or impeding organizational change. Finally, socialization helps actors determine what is important to the organization. Indeed, how individuals learn about the organization and what they learn are key signals for newcomers about what the organization values and how they should act (Tierney, 2008).

All these elements are part of a university's organizational culture. We decided to discuss only a few in this paper, namely mission, structure, governance and decision making as well as teaching and research as they are relevant for the identity of a higher education institution. The design of selected elements answers to some questions: why does the organization exist? (mission); how does the organization reach its goals? (structure, governance and decision making); what does the organization do (teaching and research) to effectively meet the needs of internal and external audiences?

Our approach is a comparative one because we think that learning from the best is not only useful but also inspiring: a model of success makes people and institutions hope that if you find the correct answers to the fundamental questions of why, how and what, there is a chance to make it. In this case, our model is Harvard University (HU), ranked first in the world as the best higher education institution. The disciple is the University of Bucharest (UB) ranked first as in teaching and second in research in Romanian higher education (2014).

\section{Learning from the best}

\section{Mission}

As mentioned before, organizational mission refers to how the institution's participants define the ideology of the university. It is an act of interpretation (with roots in the organization's history) of what the organization stands for. A mission speaks to the internal and external public about its meaning, direction and purpose. It is (or should be) an answer to a question: why does this organization exist?

A good answer to the question "why" is that of Harvard University: "The mission of Harvard College is to educate the citizens and citizen-leaders for our society. We do this through our commitment to the transformative power of a liberal arts and sciences education. Beginning in the classroom with exposure to new ideas, new ways of understanding and new ways of knowing, students embark on a journey of intellectual transformation...From this we hope that students will begin to fashion their lives by gaining a sense of what they want to do with their gifts and talents, assessing their values and interests and learning how they can best serve the world" (www.harvard.org).

As anyone can easily notice, this mission is centered on the student: he/she needs to be educated so as to become a (trustful) citizen and citizen-leader; therefore, he/she is invited to embark on a journey of intellectual transformation. It is by 
exposure to new ideas and ways of understanding along this journey that students become familiar with what happens in society and get a clearer picture of what they want to become in this life.

The mission of the UB is less clear: "The University is one of the leading higher education institutions in Romania and South-East Europe by actively contributing through research and teaching to the development and use of knowledge. The University's main objective is to offer high quality academic programs and research facilities and becoming a forefront of research and teaching. The University is an important academic institution, part of a global intellectual community working towards protecting and reinforcing academic values as well as towards promoting diversity and international collaboration" (www.unibuc.ro).

The mission of the UB is focused rather on the institution itself. There is no specific reference to students as the main beneficiaries of what the university has to offer, as if the academic programs and research facilities have one single, central and important objective: to serve the university so as to become a forefront of research and teaching. Moreover, it is stated that the university is an important institution (?) that promotes values, diversity and international collaboration as part of a global community. It may be an important institution but in what context? Compared to what? We believe that it may be useful to redefine the mission of the university as long as there is no doubt that institutions of higher education are meant first of all to educate students. How they do it or if they become important while they are doing it is rather a different story.

Unlike business organizations, higher education institutions do not work with products and services; instead, they work with people and their potential. By modeling this potential with specific tools, universities contribute directly to creating individual personalities and characters, professionals and citizens. This is the reason why we believe that the answer to the question why the university exists is important to be clearly stated in its mission. Second, because universities work with young people, we think that when sharing their mission, this should be a source of inspiration: we educate students and offer them everything they need to find their own identities and grow; in the end, it is these young educated people that will be in charge of tomorrow. We believe that a convincing answer to the question why may help universities build the foundation of trust, as a social glue that makes the system work (Tierney, 2008).

\section{Structure, governance and decision-making}

Universities are entities that by definition should explicitly promote values such as autonomy and freedom, encourage cooperation between departments and faculties and support access to information and communication between administrators and faculty.

According to Armstrong (1995), an organizational culture has an influence on the organizational structure and operational systems within an organization. The structure seems to emphasize certain values such as flexibility, freedom and cooperative teamwork. It is especially the values of flexibility as opposed to rigidity and freedom as opposed to control that are emphasized in the literature (Arad et al, 1997). A high level of responsibility and adaptability in university structure also accompanies an organizational culture that allows for flexibility.

Freedom as a core value promoted by all institutions of higher education in general is manifested in autonomy, empowerment and decision making. This implies that academics are free to achieve their goals in an automatic and creative way within guidelines (Judge et al, 1997). Academics therefore have the freedom to do their work and determine procedures as they see fit within guidelines. Management should also encourage academics to be more creative and empower instead of control them (Judge et al, 1997). The degree to which they have freedom and authority to participate in decision making and in solving problems determines the level of empowerment which is positively related to the effectiveness and efficiency of higher education institutions (Arad et al, 1997).

Cooperative teams are identified by some authors as being essential for the degree to which creativity and innovation is promoted and sustained within universities. Well established teams which encompass diversity and individual talents that complement one another promote creativity in everything they do whether research or teaching (Arad et al, 1997, Mumford et al, 1997). Cross-functional teams which encourage social and technical interaction between its members can improve collective creativity which is further reflected in a course design or a project that opens a new line of research. In other words, a team's creativity depends on their way of making cooperation work with each other and other groups and sharing information. It is trust and mutual respect that make cooperation possible in a variety of forms. Again, trust as the social 
glue of organizational culture has an influence upon institutional creativity (Tierney, 2008). Academics need to understand different opinions and styles of doing things, solve conflicts, communicate effectively and be open to new ideas and question them. Such effective teamwork is partly based on the team members' skills and abilities and partly on the shared values within the group (Tushman and O'Reilly, 1997).

If a university is compared to a business organization, most often than not we have to consider rather confusing relationships between administration and faculty as reflecting disorganization, willfulness or the pursuit of self-interest in preference to college interests. Corson (1960) was among the first to identify the administration of colleges and universities as presenting "a unique dualism in organizational structure" (p. 43). Corson saw the university as including two structures existing in parallel: the conventional administrative hierarchy and the structure through which faculty made decisions regarding those aspects of the institution over which they had jurisdiction. This dual system of control was further complicated by the fact that neither system had consistent patterns of structure or delegation. The faculty governance structure on every campus was different and each administration seemed to have been established "to meet specific situations in particular institutions or to reflect the strengths and weaknesses of individuals in various echelons" (p. 45).

Although Harvard University is top of list of higher education institutions, it has only a very small administrative group at the top. Harvard is significantly decentralized with activities occurring within a few square miles of Boston and Cambridge, Massachusetts. Most employees are housed in the university's four schools. Each school has its own dean and its endowment and, in accordance with Harvard's philosophy, "every tub on its own bottom", largely controls its own destiny.

Harvard is one of the few universities in which each school chooses its own academic calendar. Each school has its fiscal autonomy and responsibility. Individual professors also have enormous autonomy and discretion. In many schools, they have almost total control over courses they teach, research they do and which activities they pursue, if any. Faculty meetings are typically sparsely attended. If a dean or a department head wants a faculty member to chair a committee or offer a new course, the request is more often a humble entreaty than an authoritative command. Everybody expects each course at Harvard to be the unique creation of an individual professor. Two schools might offer courses with the same title, covering entirely different content with widely diverging teaching styles.

It is autonomy and decentralization that allows Harvard to be extremely flexible. Each school has its own administrative structure. Administrative staff is perceived rather as a support structure that is in charge with managing resources (money, buildings and other facilities) in order to support a school's activities: teaching, research and service. Each school is managed by a dean and his/her team. Decision making related to teaching and research activities is an extremely transparent process; it also involves participation of all faculty members.

The situation looks different at UB: the self-evaluation report of the UB in 2012 has revealed that governance structures and decision-making processes are not always clear, efficient and transparent. In some cases, similar administrative tasks are carried out in a variety of departments at various levels, resulting in inefficiencies and confusion for the users of their services (SER 2012).

Administrative and academic staff experience constraints due to bureaucracy which is often attributed to the numerous and constantly changing regulations from the governments. These changes often result in a waste of time and resources. Some examples of such consequences are: delayed implementation of projects; not being able to hire academic and administrative staff despite of the high number of students and research projects; rigid budgeting and public procurement procedures. However, following the Law on Education which issued some governance and human resources arrangements and procedures to universities, UB needs to address the internal governance and decision-making within its own organization more effectively.

There is a strong awareness of the necessity to rethink the balance of responsibility between the central and faculty level. The university aims to make its administration more efficient and transparent. It is important to draw up an overview of structure of the administration and its administrative processes. University governance structures and processes should be reviewed to see whether they are functional and should be adjusted accordingly, in order to at least reduce inefficiencies.

The university should have a more coherent administrative structure serving the university community in a simple, one-stop manner. For example, maintaining one central statistical database for all institutional information including teaching, research, services, students and staff, and providing necessary analysis upon request to inform its own decision-making processes is a precondition for well-informed and timely decision-making. Having institutional statistical data gathered and 
kept in different departments and research units is not helpful for entering quality management processes or helping decision-making at the UB (SER 2012).

There should be a better distribution of academic responsibility and decision-making between the Rectorate and the faculties on the one hand while it should be investigated if some additional practical services should be provided by the central level, on the other hand. There is an example of this with the research office where one office is located centrally at the university and aims to assist academics with various grants. Research grant management is an important part of the academic work portfolio, but it is difficult to have just one central office without administrative staff in the faculties who can help academics to submit and administer external grants.

It is important to note that "governance" as well as management and administrative staff should serve and support teaching, research and service of the academic community at the UB.

\section{Teaching}

HU developed Harvard Initiative for Learning and Teaching (HILT). This structure's mission is to catalyze innovation and excellence in teaching and learning at Harvard. Its four goals are: to build on Harvard's strengths in teaching and learning; to meet the educational needs of students (both technological and pedagogical; to strengthen the science of learning and to develop a robust network at Harvard around teaching and learning innovation. These challenges require the combined efforts of students, faculty and staff and the thoughtful coordination of programs, centers, departments and schools with each other and the University as a whole. As HILT's President, Drew Faust, mentioned: "We must deploy Harvard's exceptional scholarship to redefine teaching based on the ideas, evidence and technology of today's world".

Over the next ten years, HILT aims to have demonstrably seeded hundreds of local innovations and experiments; to facilitate the "institutionalization" of innovations and experiments that are successful such that they become self-sustaining; to have developed a large community of practice around teaching and learning excellence that involves all Harvard schools; to facilitate high quality research on learning and teaching that is used by Harvard instructors and students and beyond.

HILT uses a variety of tools for accomplishing its mission and goals. One of them is the Spark Grants, offered on a semesterbasis. These are awards designed to help "spark" promising teaching and learning projects from idea to reality and position innovations for future success. To create the best $21^{\text {st }}$ century learning and research environment at Harvard, the Office of the Vice Provost for Advances in Learning (VPAL) offers faculty and students support and services. The number of tools and means to support innovation that Harvard has already created is quite impressive and they are functional and efficient: Teaching and Learning Consortium network, HILT Spark Grants, Scholar to Practitioner Speaker Series (a web page for expert scholar speakers), Talking about Teaching Series (a seminar that explores pedagogical connections across disciplines and schools), University-wide video infrastructure support, to name just a few.

Teaching at $\mathrm{HU}$ is extremely challenging. For example, Harvard Business School (HBS) offers about 100 courses in economics. These courses are created by faculty and undergo discussions and improvement before their final approval. Only a small number of courses are obligatory; most of them are electives. And, if these courses are to survive along the way, students need to see these courses as new, useful and attractive; which makes cooperation between faculty and departments possible (because academics work together at course design and course improvement) as well as competition (only the most promising and attractive courses survive). In this case, both cooperation and competition are needed in order to support the university's mission and performance.

At the UB, not even at faculty level can we speak of autonomy and freedom in decision making; therefore, teaching is not always easy. For example, creating and implementing a new course is a very long and complicated process. It may be a good course, new and attractive with a great value for students and an exquisite learning content. You can teach this course only within an existing specialization and only if the course is mentioned in the ARACIS guidelines. Besides, there is no prior process of peer review and content improvement. No one evaluates course novelty, usefulness and attractiveness; which in turn makes writing new courses a much less interesting activity as long as there are no mechanisms of support at management level (programs are already stuffed with courses); neither at department level (there are no teams to evaluate course content and offer feedback to the author (s). Therefore, if there is no preoccupation and no mechanisms of support, creativity has little chance of manifesting itself so as to serve both students and university. 


\section{Research culture and support}

The Directors of Research at HU are responsible for fostering the university's intellectual community and research culture, encouraging research that addresses important global and multidisciplinary questions and supporting individual faculty in their research programs. For example, in response to the faculty culture report, the Directors of Research at Harvard Business School (HBS) engaged in a series of discussions of their aspirations for the HBS research culture and how to enhance that culture. They presented their aspirations and ideas to the faculty and held a series of 10 small group discussions during the fall 2013 to solicit feedback and additional ideas. During the spring term they held two focus group meetings with the faculty who organize research labs, engaged the Dean's Management Group and convened the School's Unit Heads for further discussions to help shape their ideas. In May 2014, the Senior Associate Dean for Research presented the outline of three experiments to all the faculty:

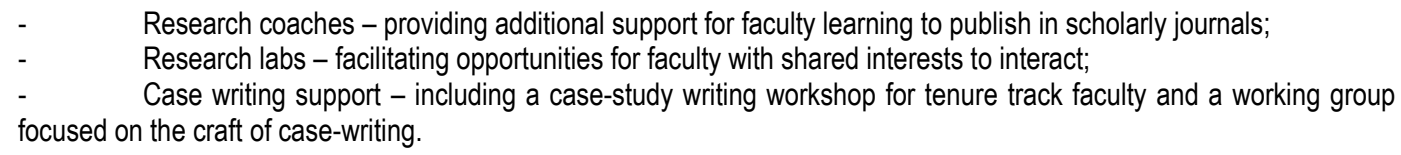

Additional activities to support research at $\mathrm{HU}$ in recent years have included:
- $\quad$ Increasing the visibility of inspirational research through an annual School-wide research symposium;
- $\quad$ Hosting the Course Development Research (CORE) seminar to provide a forum for faculty engaged in course development research to discuss early stage work with colleagues throughout the School;
- $\quad$ Sponsoring research conferences, many with a multidisciplinary focus, that academics and practitioners attend;
- $\quad$ Faculty Immersion Experience Programs (IXP) provide opportunities for faculty learning and, in the case of international IXPs, to reduce barriers to conduct international research:
- $\quad$ The Global Research Fellowship Program provides opportunities for faculty to pursue in-depth research and course development projects outside the US. The fellowships allow for a true immersion experience by providing funding for a one to nine month international stay;
- $\quad$ Faculty members are provided with an annual stipend as a supplement to their research budget that offers flexibility to cove research-related expenses that might not otherwise be covered by the research budget, such as technology purchases.

According to the UB's internal regulation, the research strategy at the university is drawn up normally by the Scientific Board. It is based on the integration of the yearly's programs of the university's research centers. The strategy has to be approved by the University's Senate (art. 7, UB Research Regulation).

Research at UB takes place in various units within the departments and faculties (art. 4, UB Research Regulation). Researchers are affiliated to both a research center and a faculty. According to the SER (2012), research is coordinated by a variety of structural arrangements, such as institutes (e.g. Institute of Classical Studies), laboratories, research centers, project units and consultancy centers. In some faculties, research centers create good conditions for research while in others, research centers do not seem to be functioning. This structure for research encompassing different entities may be too complicated to operate effectively and to properly manage. Therefore, the relationship between different research entities should be clarified to ensure reasonable responsibility.

Research management at UB is decentralized. The administrative and financial management of the research projects is carried out centrally at the university level by the Office of Research and Technology Transfer. According to a recent survey (2012), academics are concerned with project management procedures that are cumbersome and may sometimes jeopardize the success of research projects. The lines of communication and responsibilities are unclear; thus, a great deal of time is needed for academics to run a research project.

In some faculties, the doctoral and postdoctoral researchers are engaged in externally funded research projects, both nationally and internationally. Faculty members generally attend international conferences and organize various scholarly events. But, in some faculties, research activities are far from being impressive. Publishing in foreign language journals is always a challenge. For quite a few, publishing internationally is a new type of activity, the rules of which they need to learn, in addition to all their other responsibilities. Since the assessment of research has only recently started, academics feel an impetus to get involved in research projects and belong to research centers. But the limited resources at national level, 
payment disruptions linked to the EU structural funds' schemes, restrictions to hire new staff as well as having very limited capital investments in infrastructure for the past few years have limited the research performance at the UB.

Given the limitations, the university should try to create more possibilities for research and support mechanisms, especially in faculties that have been less attractive so far.

Research opportunity is unevenly distributed across the university - in some disciplines there is more opportunity while in others opportunity is much less present. If the UB wants to offer research-based education, it needs to improve research in all fields, especially in the newer faculties. There should be an effort to create and increase research capacity in all faculties. Most faculties and faculty members need support mechanisms in this regard.

Although some examples of European-funded research projects can be found at the UB, it is important to make better use of available funding from outside the university and the Ministry of Education.

It is also vital to enhance the research development of young academic staff. Junior academics are generally overloaded with teaching responsibilities at the time when they should be given more room for research and publishing. Therefore, a redistribution of teaching loads across the different levels could be helpful. Perhaps more senior academics could increase their teaching loads to support upcoming talent. In several European countries, such as Germany and Denmark, but also in the US, junior academics have lower teaching loads than senior academics.

The quality of teaching and research depends, to a great extent, on the institutional support: money, buildings, infrastructure, networks, etc. If in the case of $\mathrm{HU} 58 \%$ of faculty are very satisfied and $23 \%$ are satisfied with opportunities to innovate in teaching (2013 Harvard Faculty Climate Survey Results), in the case of UB only $15 \%$ of faculty are very satisfied and $13 \%$ are satisfied with the same opportunities. $48 \%$ of Harvard professors are very satisfied and $33 \%$ are satisfied with the quality of technical and research staff while at the UB only $19 \%$ declare that they are very satisfied and $14 \%$ declare satisfaction regarding the quality of technical and research personnel. It is also interesting to notice that at Harvard's, the quality of support and administrative staff is perceived as very satisfactory by $48 \%$ and satisfactory by $29 \%$ of professors. In the case of UB, only $9 \%$ of professors are declare high levels of satisfaction and $4 \%$ are satisfied with the quality of support and administrative personnel (Coman, 2016).

\section{Conclusions}

Higher education institutions and business organizations have organizational cultures that differ in terms of mission, external environment, means to achieve objectives, image of the organization, management processes, interpersonal relationships and leadership.

We started with the idea that in higher education, to learn from the best means not necessarily to replicate a model of success, but rather to get inspired by and discover strategies, tools, attitudes and values that may contribute to building an organizational culture open to creativity and innovation. We decided to focus only on those elements of organizational culture that may offer answers that help the university shape its identity: the mission (why does the university exist?); structure, governance and decision making (how does it reach its mission and goals?); teaching and research (what does it offer?).

We discussed the answers to these questions in the specific cases of Harvard University as the leader in research and teaching in the academic world and the University of Bucharest, ranked first in teaching and second in research among higher education institutions in Romania.

What are the lessons that academics and administrators of UB may learn from the best? First, we need to reaffirm our determination to serve students, to educate them using all the necessary tools to help them find their way in life as selfaccomplished individuals, professionals and citizens. To (re)affirm the reason why we exist as a higher education institution (the answer to the question "why") is part of the organizational culture. The answer to why may inspire students and helps us all develop trust as a social glue that holds the organization together.

Second, we should design better structures of governance and more flexible systems of communication and decision making. With structures and systems based on values such as autonomy and freedom, we should express this freedom in everything that is related to teaching and research, including hiring personnel, creating and implementing new courses, 
easier access to university research grants. This is the answer to the question "how": transparency in decision making, access to information and flexible administrative and management structures. In the case of UB, a convincing answer to the question "how" would be an indicator of an organizational culture prepared to face change; open to innovation; supportive in reaching organizational mission and goals.

Last but not least, we should learn that research and teaching need adequate mechanisms of support. While it is about new programs and fields of teaching, new national or international grants, new teaching and learning systems and personnel, all need mechanisms of implementation and support. Because if you lack adequate support, you cannot wait for outstanding results to happen. You cannot build trust unless you prove that where there is initiative and innovation, there is also a mechanism to support it; where there is opportunity, there are also tools to help that opportunity turn into something useful for students and faculty.

Inspiration, openness, support - these are the organizational coordinates that we should work on with determination and enthusiasm in the years to come; hopefully, we will make it to the top.

\section{References}

[1] Ahmed, P. K. (1998). Culture and Climate for Innovation. European Journal of Innovation Management, 1(1): 30-43.

[2] Arad, S., Hanson, M. A., Schneider, R. J. (1997). A Framework for the Study of Relationships Between Organizational Characteristics and Organizational Innovation. The Journal of Creative Behavior, 31(1): 42-58.

[3] Armstrong, M. (1995). A Handbook of Personnel Management Practice. Lodon:Kogan Page.

[4] Becher, T. (1981). Towards A Definition of Disciplinary Cultures. Studies in Higher Education, (6): 109-122.

[5] Bourdieu, P. (1977). Systems of Education and Systems of Thought. International Social Science Journal, 19: 338-358.

[6] Chaffey, E. E. and Tierney, W. G. (1988). Collegiate Culture and Leadership Strategy. New York: Macmillan.

[7] Chiritescu, D. D. (2016). In asteptarea noului Keynes. Retrieved from http/:www.dilemaveche.ro in February 12, 2016.

[8] Clarck, B. R. (1970). The Distinctive College. Chicago: Aldine.

[9] Clarck, B. R. (1980). The Organizational Saga in Higher Education. In H. Leavitt (ed), Readings In Managerial Psychology. Chicago: University of Chicago Press.

[10] Clarck, B. R. (1984). Perspectives in Higher Education. Berkeley: University of California Press.

[11] Coffey, R. E., Cook, C. W., Hunsaker, P. L. (1994). Management and Organizational Behavior. Irwin: Burr Ridge.

[12] Corson, J. J. (1960). Governance of Colleges and Universities. New York: McGraw-Hill.

[13] Coman, A. (2016). Organizational Culture Survey, unpublished.

[14] Freedman, M. (1979). Academic Culture and Faculty Development. Berkeley: University of California Press.

[15] Furnham, A. and Gunter, B. (1993). Corporate Assessment: Auditing a Company's Personality. London: Routledge.

[16] Gaff, J. G. and Wilson, R. C. (1971). Faculty Cultures and Interdisciplinary Studies. Journal of Higher Education, 42: 186-201.

[17] Geertz, C. (1973). The Interpretation of Cultures. New York: Basic Books.

[18] Hellriegel, D., Slocum, J. W., Woodman, R. W. (1998). Organizational Behavior. Cincinnati: South-Western College. 
[19] Judge, W. Q., Fryxell, G. E. and Dooley, R. S. (1997). The New Task of R\&D Management: Creating GoalDirected Communities for Innovation. California Management Review, 39(3): 72-85.

[20] Kreitner, R. and Kinicki, A. (1992). Organizational Behavior. Irwin: Homewood.

[21] Lundy, O. and Cowling, A. (1996). Strategic Human Resource Management. London: Routledge.

[22] Martell, C. (1989). Achieving High Performance in Library Work. Library Trends, 38(1): 73-91.

[23] Martins, E. C. (2000). The Influence of Organizational Culture on Creativity and Innovation in a University Library. Pretoria: University of South Africa Press.

[24] Martins, E. C. and Terblanche, F. (2003). Building Organizational Culture that Stimulates Creativity and Innovation. European Journal of Innovation Management, 6(1): 64-74.

[25] Mumford, M. D., Whetzel, D. L. and Reiter-Palman, R. (1997). Thinking Creatively at Work: Organization Influences on Creative Problem Solving. The Journal of Creative Behavior 31(1): 7-17.

[26] Office of the Senior Vice Provost. (2014). 2013 Harvard Faculty Climate Survey Results. Retrieved from https://www.harvard.org. on February 12, 2016.

[27] Pheysey, D. C. (1993). Organizational Cultures: Types and Transformations. London: Routledge.

[28] Read, W. H. (1996). Managing the Knowledge-Based Organization: Five Principles Every Manager Can Use. Technology Analysis and Strategic Management, 8(3): 223-232.

[29] Robbins, S. P. (1996). Organizational Behavior: Concepts, Controversies, Applications. Englewood Cliffs, NJ: Prentice-Hall.

[30] Sathe, V. (1985). Culture and Related Corporate Realities: Text, Cases and Readings on Organizational Entry, Establishment and Change. Irwin: Homewood.

[31] Schein, E. H. (1985). Organizational Culture and Leadership. San Francisco: Jossey Bass.

[32] Schuster, F. E. (1986). The Proven Connection between People and Profits. New York: Wiley.

[33] Senge, P., Kleiner, A., Roberts, C., Ross, R., Roth, G., Smith, B. (1999). The Dance of Change: The Challenges of Sustaining Information in Learning Organizations, A Fifth Discipline Resource. London: Nicholas Brearley.

[34] Sinek, S. (2009). Start with Why: How Great Leaders Inspire Everyone to Take Action. Amaltea: Bucharest.

[35] Tiernay, W. G. (2008). Trust and Organizational Culture in Higher Education. Center for Higher Education Policy Analysis: University of Southern California)

[36] Tierney, W. G. (1988). Organizational Culture in Higher Education: Defining the Essentials. Journal of Higher Education, 59(1): 2-21.

[37] Tierney, W. G. (1994). Organizational Culture and Interpretive Strategy: Implications for Latin American Higher Education. Revista IGLU, 6(April): 85-100.

[38] Tushman, M. L. and O'Reilly, C. A. (1997). Winning through Innovation: A Practical Guide to Leading Organizational Change and Renewal. Boston: Harvard Business School Press.

[39] University of Bucharest. (2012). The Self-Evaluation Report (SER). Retrieved from https://www.unibuc.ro on February 12, 2016.

[40] Valimaa, J. (1988). Culture and Identity in Higher Education. Higher Education, 36(2): 119-138. 